\title{
Peertechz
}

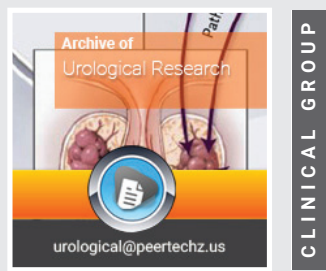

\section{Malakoplakie of the ovary: Case report and litterature review}

\author{
EK Laying', RA Gayito Adagba'*, JB Djiepti', J Boboe', MA \\ Ganglo', L Guedehoussou', MUB Megninou' ${ }^{2}$, AP Karka ${ }^{2}$, H \\ Kassa ${ }^{1}$, TK Hessou' ${ }^{1}$ and JDG Avakoudjo ${ }^{3}$
}

'Department of General Surgery, Saint Jean de Dieu Hospital in Tanguiéta, Benin

${ }^{2}$ Hôpital Saint Padre Pio de N’Dali, Benin

${ }^{3}$ Hubert Koutoukou Maga National University Hospital Center, Benin

Received: 24 March, 2021

Accepted: 07 April, 2021

Published: 10 April, 2021

*Corresponding authors: RA Gayito Adagba, Department of General Surgery, Saint Jean de Dieu Hospital in Tanguiéta, Benin,

E-mail: gayito_castro@yahoo.fr

Keywords: Malakoplakie; Ovaire; Anti; Inflammatory; Michaelis; Gutmann

https://www.peertechzpublications.com

\section{Summary}

Malakoplakie is a chronic granulomatous inflammatory disease, which usually affects the genitourinary tract and less frequently other sites such as, kidney, ureter bladder, bone, lung, skin, gastrointestinal tract and ovary.

We report a case of ovarian malakoplakie in a patient on anti-inflammatory admitted to the emergency room for a painful hypogastric mass, from the left iliac pit

\section{Introduction}

Malakoplakie, also known as malakoplasia [1], is an inflammatory granulomatous disease induced by defective phagocytic macrophagic activity. It usually affects the whole body, but the genitourinary tract in about $75 \%$ of reported cases. Other organs such as the gastrointestinal tract, thyroid, pancreas, liver, brain, lymph nodes, adrenals, skin, bones, backpertis and ovary are less common. It represents a deficit in the macrophagic digestion of bacteria, but its precise pathogenesis is not yet clear [1]. Its treatment is essentially based on antibiotic therapy [2]. We report a malakoplakie observation in order to expose the difficulties associated with its management in a resource-limited environment.

\section{Clinical case}

This was a 41-year-old patient who had been admitted to the emergency room for pelvic pain for a month and was operating in a febrile setting. The accompanying signs were digestive type made of diarrhea and vomiting. No urinary symptoms were found. Clinical examination showed a patient with an alteration of the general condition, a hyperthermia at 39 degrees, a painful swelling of the left iliac pit with abdominal defense located in left iliac pit. Biology had shown hyper leucocytosis at $15,000 / \mathrm{mm}^{3}$ predominantly polynuclear neutrophils associated with anemia at $5 \mathrm{~g} / \mathrm{dL}$. The abdominal ultrasound had been objectified: a localized abscess in the pelvis with bilateral pyelolo-calicial dilation without visible barrier, right and left inguinal adenopathies without obvious compression, and medium-abundance ascite. The surgical indication retained; the patient benefited from an exploratory laparotomy that found a voluminous peritoneal abscess at the expense of the left ovary. A wash of the peritoneal cavity associated with a left oophorectomy was performed. Cytobacteriological examination of abscess fluid had isolated gram-negative bacillus such as Escherichia coli. Cytobacteriological examination of the urine was sterile. The surgical suites were simple with apyrexia and an amendment of abdominal pain under double probabilistic antibiotic therapy. The patient was discharged on the 6th day post-operative.

Anatomopathological examination one month after the operation of the exeresis was found: ovarian tissue with large 
outbreaks of inflammation, in which histiocytes predated and lymphocytes were found in smaller quantities. In the cytoplasms of macrophages, there were bodies of MichaelisGutmann, pathognomonic of malakoplakie (Figures 1,2).

Remote evolution was towards a recurrence of symptomatology with chronic parietal suppuration and armour of the pelvis. The patient was remissioned on fluoroquinolonesbased antibiotic therapy (ciprofloxacin 500mg every 12 hours) and metronidazole 500mg every 8 hours scheduled for three weeks. In front of the abdominal-pelvic armour, a surgical abstention was indicated with continued medical treatment. Under this treatment the evolution gradually turned to hematuria, a unilateral edema of the left pelvic limb. The requested abdominal-pelvic scanner could not be carried out due to a lack of financial means. The patient was discharged 3 days later against medical advice.

\section{Discussion}

Malakoplakie is originally a Greek word meaning "soft plate." It is an unusual inflammatory disease that was initially described as affecting the bladder. It can be observed at any age with a peak frequency at the age of fifty. Both sexes can be achieved, but with a preference for the female sex [3]. The case described in our observation had interested a 41-year-old woman.

In 1902, Michaelis and Gutmann discovered during the autopsy of two women with a long history of cystitis, curious

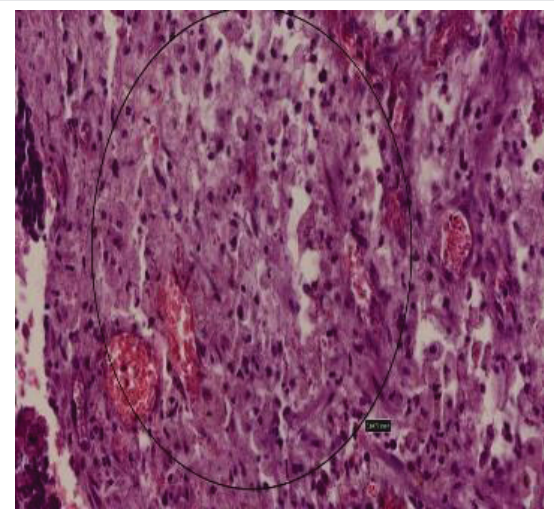

Figure 1: Inclusions of Michaelis-Gutmann in the cytoplasm of histiocytes and stroma.

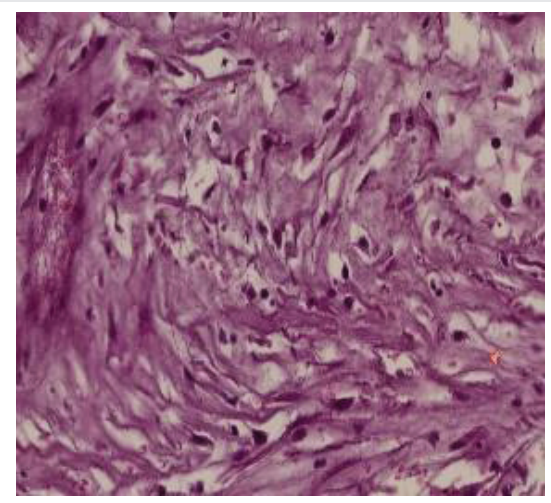

Figure 2: Area with more macrophages and fibrosis. lesions in the bladder [4] before reporting cases of damage to the entire urogenital system, the digestive system, the skin, lungs, bones and mesenteric ganglia [5].

Extra-urinary lesions are less common and occur in $40 \%$ of cases. They are of interest to the digestive tract in $20 \%$ of cases and backperittisy in $10 \%$ of cases [3]. Isolated cases have been reported in the skin, vulva, vagina, endometrial, adrenal and brain [6].

Favourable factors such as intercurrent disease or immunosuppression were reported in $40 \%$ of cases by Long and Stanton [7]. The use of long-term anti-inflammatory in our patient could be considered in our case as a factor promoting a decrease in immunity and therefore of the disease.

Recent cases have been reported in heart, kidney and AIDS transplant patients [8].

Malakoplakie does not clinically offer any specificity [7]. The tell-tale signs are most often a function of the affected organ. Retroperitoneal impairment most often occurs as an evolutionary complication, by locoregional extension of a multifocal malakoplakie at uro-genital or digestive starting point [9]. This will result in a pollakiuria and urination emergency with hematuria or urinary tract infection in case of vesiacal damage or low back pain associated with a fever when it comes to kidney or ureter damage.

Although exact pathogenesis is not known, malakoplakie probably results from an abnormality in the response of macrophages to a urinary tract infection especially to $\mathrm{E}$. Coli [10]. It seems that malakoplakie is the morphological manifestation of the deficit of factors involved in macrophagic digestion. Cyclic guanosine emonophosphate (GMPc) is necessary for the function of lysosomial microtubules and a GMPc deficiency has an inhibitory effect on phagocytosis. Cholinergics, serotonin and ascorbic acid increase intracellular levels of GMPc and promote phagocytosis. Corticosteroids, adrénégics, prostaglandin $\mathrm{E}$ and histamine, on the other hand, decrease intracellular levels of GMPc thus inhibiting cellular digestion and thus promoting the onset of the disease [6].

The diagnosis is anatomo-pathological. At microscopy, the lesion is characterized by large histiocytes called "Von Hansemann" cells with small intra and extra-cytoplasmic basopic inclusions or "Michaelis-Gutmann" bodies that are pathognomonic [6], such is the case observed in our study on the left ovary.

The lack of completion of the abdomino-pelvic CT scan did not allow us to take stock of the urinary lesions and to assess the renal resonance of the parenchymatous and ureteral lesions especially since the ultrasound had revealed bilateral ureterohydronephrosis.

The treatment of malakoplakie is based on antibiotic therapy adapted to the found germ and possessing good intracellular penetration. Medical treatment is currently offered as a first-line, based on the use of antibiotics adapted to the germs responsible: most often it is fluoroquinolones or

Citation: Laying EK, Gayito Adagba RA, Djiepti JB, Boboe J, Ganglo MA, et al. (2021) Malakoplakie of the ovary: Case report and litterature review. Arch Urol Res 5(1): 010-012. DOI: https://dx.doi.org/10.17352/aur.000030 
cotrimoxazole trimethophyprime [11]. The addition of ascorbic acid to these drugs appears to improve the performance of treatment [9]. Immunosuppressive treatments should be discontinued whenever possible. In case of abscess, drainage may be indicated. Surgical treatment is indicated in case of destruction of the affected organ [8]. In our case, we had used fluoroquinolones with the cessation of anti-inflammatory drugs. Exeresis of the affected organ may be necessary as the left oophorectomy performed in our case followed by drainage of the peritoneal cavity. Unfortunately, appropriate antibiotic therapy was instituted with a little delay and was not always well followed, therefore not allowing good infection control.

The evolution can be made towards aggravation by impacting on the neighboring and compression organs of the pelvis [12]. This has been observed in our patient. Unilateral edema in our patient may be related to neurovascular extrinsic compression. Departure against medical advice is a common fact on the periphery. As in our current case, it does not allow for good patient follow-up or effective assessment of management.

\section{Conclusion}

Malakoplakie is a rare condition. Its management is medical and sometimes surgical. The follow-up of our patient was not satisfactory due to a departure against medical advice. This is a behaviour to be discouraged under our skies because it does not allow a good evaluation of the treatments instituted.

\section{References}

1. Ammor I, Amrani M, Belabbas MA, Ai-Aoui A, Benyafua T (1999) Colic malakoplakia:Malakoplakie colique: A propos d'un cas avec revue de la littérature. Acta Endoscopica 29: 151-156.
2. Amna MB, Hajri M, Oumaya C, Anis J, Bacha K, et al. (2002) La malokoplakie génitourinaire à propos de dix cas et revue de la littérature. Ann Urol 36: 388 391. Link: https://bit.ly/3t1AXin

3. Long JP, Althausen AF (1989) Malacoplakia: A 25-year experience with a review of the literature. J Urol 141: 1328-1331. Link: https://bit.ly/2OrJOea

4. Pogu B, Francois O, Chautard D, Croue A, Pocholle P, et al. (1993) Malakoplakie vésicale a forme tumorale. À propos de deux cas. Prog Urol 3: 276-283. Link: https://bit.ly/3dL7jYc

5. Michaelis LX, Gutmann C (1902) Ueber Einschlüsse in Blasentumoren. Z Klin Med 4: 208

6. Albitar S, Genin R, Fen-Chong M, Schohn D, Riviere JP, et al. (1997) The febrile patient presenting with acute renal failure and enlarged kidneys: another mode of presentation of malakoplakia. Nephrol Dial Transplant 12: 1724-1726. Link: https://bit.ly/31QSjmf

7. Sarkis P, Nawfal G, Mouaccadieh L, Daou I, Zanati M (2012) Malakoplakie rénale, urétérale bilatérale et vésicale : à propos d'un cas et revue de la littérature. Prog Urol 22 : 970-973. Link: https://bit.ly/39Mr40f

8. Mackay EH (1978) Malakoplakia in ulcerative colitis. Arch Pathol Lab Med 102: 140-145. Link: https://bit.ly/3fPBi3Z

9. Elktaibi A, Barki A, Mesmoudi S, Harchichi N, Jahid A, et al. (2010) La Malakoplakie Rétropéritonéale Pseudotumorale. Afr J Urol 16: 65-68. Link: https://bit.ly/39SBVpM

10. Hartman D (1985) Radiologic pathologic correlation of the infectious granulomatous diseases of the kidney: III and IV. Monogr Urol 6: 26.

11. Diwakar R, Else J, Wong V, Came A, Banerjee D, et al. (2008) Enlarged kidneys and acute renal failure: why is a renal biopsy necessary for diagnosis and treatment? Nephrol Dial Transplant 23: 401. Link: https://bit.ly/3wy6ASX

12. Vallorosi CJ, Putzi MJ, Wolf JS (1999) Renal malakoplakia. Tech Urol 5: 434.

Discover a bigger Impact and Visibility of your article publication with Peertechz Publications

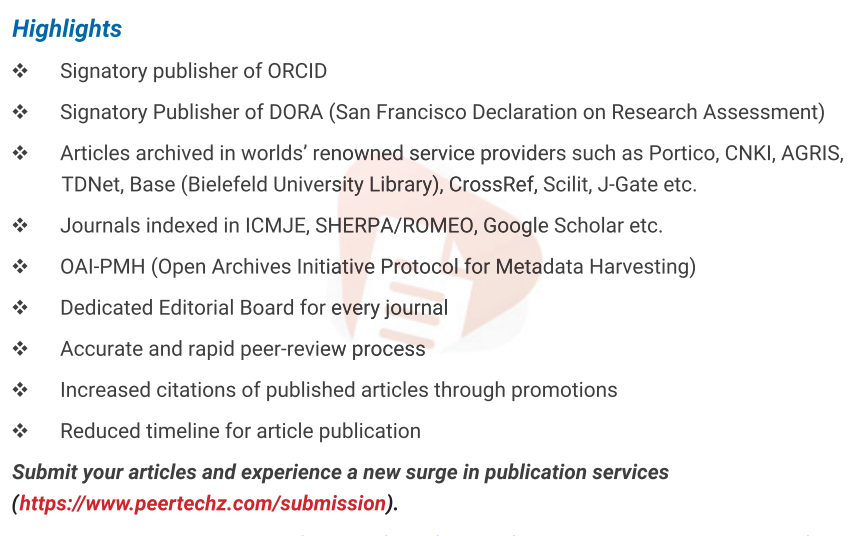

Peertechz journals wishes everlasting success in your every endeavours. 